\title{
Does the Carbon Footprint Enhance the Sustainability Food Production and Transportation Service System? Real Buying Experiment in Japan
}

\author{
Keiko Aoki ${ }^{1}$ and Kenju Akai ${ }^{2}$ \\ ${ }^{1}$ Institute of Social and Economic Research, Osaka University, Osaka, Japan \\ k_aoki@iser.osaka-u.ac.jp \\ ${ }^{2}$ Graduate School of Engineering, The University of Tokyo, Tokyo, Japan \\ akai@css.t.u-tokyo.ac.jp
}

\begin{abstract}
To examine whether the carbon footprint induce the sustainability local food production and service system, this study investigate the relationship between consumers' environmental consciousness and willingness to pay for carbon dioxide emissions on food products by using a choice experiment under the real buying experiment. The results show that consumers with higher environmental consciousness value the higher WTP for the reduction of carbon dioxides.
\end{abstract}

Keywords: Carbon footprint, Local food system, Transportation, Choice experiment, Experimental economics.

\section{Introduction}

A carbon footprint aims to indicate and visualize the amounts of carbon dioxide $\left(\mathrm{CO}_{2}\right)$ emissions caused in the process from production to disposal as the life cycle of the food products in order to motivate consumers and producers to buy and produce the food with lower emissions, respectively.

Onozuka and McFadden (2011) show that increasing the $\mathrm{CO}_{2}$ emissions induces the negative WTP for the food consumption but local labels mitigate that negative impact [1]. Thus, consumers have a preference for the local foods. This is the biggest difference in the carbon footprint between food products and non-food products such as electric products and other daily commodities. The local food system, that is, local productions for local consumptions, maintains the food as more fresh and the taste as better, which attracts consumers more to the local foods than to the foods produced in the far distance. Growing the local food system induces a few energy spending for the transportation and larger consumptions with reducing the waste of disposals, which more advances to mitigating the $\mathrm{CO}_{2}$ emissions and enhances the sustainable food system. In this meaning, carbon footprints will become important role to disseminate the local food production and service systems to attain the sustainability food system. 
There is, however, still open question whether the consumers want to reduce $\mathrm{CO}_{2}$ emissions caused from the transportation and local food system is proceeding. To examine this question, a simply hypothesis is tested in this study. It is that consumers with higher environmental consciousness exhibit the higher willingness to pay for the reduction of $\mathrm{CO}_{2}$. To examine this hypothesis, there are the three steps in this study as follows.

First, the selected consumers' ecological purchase behaviors scale originally developed by Roberts (1996) is used to evaluate environmental consciousness for consumers [2].

Second, the choice experiment is used to estimate the value of the carbon dioxide emissions. The choice experiment consists of three alternative oranges including two attributions; price and amounts of $\mathrm{CO}_{2}$ emissions. The choice experiment approach used in this study is a type of stated preference method [3] useful for effectively overcoming certain biases (e.g., strategic bias, compliance bias, and warm glow bias).

Following Experimental Economics method, the choice experiment condition is real buying experiment. In this experiment, respondents are given real money and buy one of three oranges in 12 times to take them home.

The seminal experimental study of generally called eco-labels is Cason and Gangadharan (2002), which find the eco-labels clear the market adverse selection caused from the information asymmetric between consumers and producers [4]. In the food markets, for example, experimental studies include fair trade [5, 6] , organic labels [7], genetically modified label [8-11]

The remaining paper is organized as follows. Section 2 explains the survey and experimental design and procedures. Section 3 describes the empirical model structure. Section 4 analyzes the results, and Section 5 summarizes the conclusions and discussions.

\section{Experimental Design and Procedure}

The experimental design and procedures replicate the previous study of Aoki et al. (2010), who find the hypothetical bias for the consumers' reactions of information of sodium nitrite on the ham [12].

Figure 1 shows the example of designated choice sets and the alternatives are three types of oranges A, B, and C. ${ }^{1}$ The type of oranges is called Satsuma mandarin oranges (Citrus unshiu Marc.), which is the representative domestic fruit in Japan. ${ }^{2}$ Each alternative constitutes two types of attributions; the price and the amounts of $\mathrm{CO}_{2}$ emissions. The levels of the price attribute have three values: 25, 35, and 45 JPY per one unit of orange. These levels are based on the prices of oranges in the three largest supermarkets around Osaka University.

\footnotetext{
${ }^{1}$ Following Aoki et al. (2010), "no-purchase" alternative is not added in the choice experiment.

2 Each orange was approximately $7 \mathrm{~cm}$ in diameter and its weight was approximately $100 \mathrm{~g}$. Its color was orange with a bluish tinge. The sugar content in them was approximately 9 to 11 brix.
} 


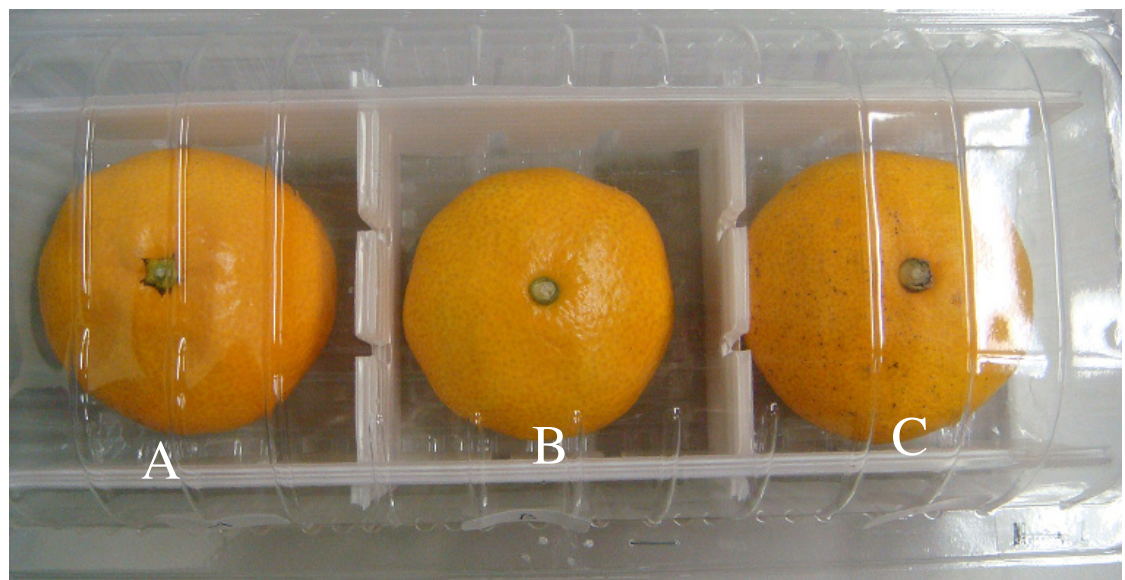

\begin{tabular}{|l|c|c|c|}
\hline & Orange A & Orange B & Orange C \\
\hline Price & 35 & 25 & 45 \\
\hline Carbon dioxide emissions & 30 & 20 & 40 \\
\hline I would choose... & \multicolumn{1}{|c|}{$\square$} & $\square$ & $\square$ \\
\hline $\begin{array}{l}\text { The most important reason } \\
\text { affecting my choice }\end{array}$ & $\begin{array}{l}\square \text { Price } \square \text { Carbon dioxide emissions } \\
\square \text { Others [A reason: }\end{array}$ & $\begin{array}{c}\square \text { Appearance } \\
]\end{array}$ \\
\hline
\end{tabular}

Fig. 1. An example of choice sets and oranges

The amounts of the $\mathrm{CO}_{2}$ attribute also have three values; $20 \mathrm{~g}, 30 \mathrm{~g}$, and $40 \mathrm{~g}$ per one unit of orange, which are calculated the four stages of their life cycle: production, fruit sorting and box packing, transportation, and packaging. ${ }^{3}$ To cope with a rule for the prohibition of deception in Experimental Economics, three different places producing oranges are actually selected to make the difference of $\mathrm{CO}_{2}$. Since the carbon footprint is to be prepared in Japan, the $\mathrm{CO}_{2}$ emissions are first calculated on the life cycle assessment (LCA) to select those places. Then, the oranges are selected three famous places; Kumamoto, Ehime and Wakayama. The experiment is conducted in Osaka prefecture that is the most far from Kumamoto (about $800 \mathrm{~km}$ ), second from Ehime (about $380 \mathrm{~km}$ ) and third from Wakayama (about 100km). Thus, the transportation causes the main difference of $\mathrm{CO}_{2}$ emissions in this study. The total $\mathrm{CO}_{2}$ emissions are calculated as 34g, 32g, 23g in Kumamoto, Ehime and Wakayama, respectively. Based on these three values, the three values are employed as $20 \mathrm{~g}, 30 \mathrm{~g}$, and $40 \mathrm{~g}$. Respondents, however, does not receive the places nor the $\mathrm{CO}_{2}$ emitted in each process to make respondents focus on only price and the total amounts of $\mathrm{CO}_{2}$ emissions in the food products.

3 The levels of $\mathrm{CO}_{2}$ emissions of oranges during their sale in supermarkets and stores are not added because a number of other goods are present there. 
A full factorial design with three levels of prices and three amounts of $\mathrm{CO}_{2}$ emissions constructed 729 alternative management combinations. Since it constitutes an unreasonably large design in practice, a D-optimal fractional factorial design with 24 alternatives is developed and separated into two blocks of 12 choice sets by using Design Expert (version 7). Therefore, each respondent choose one of three oranges and this repeats 12 rounds. The respondents received 120 JPY as endowment in order to purchase one unit of orange and a plastic package contained three types of oranges. The package was clear to see inside but sealed to keep respondents' hands off. They selected one of the oranges they wanted to buy. The price of the oranges they selected is deducted from the endowments and the total remaining money is paid as their earnings at the end of the experiment.

After twelve choice sets completed, respondents answer the survey questions about environmental consciousness (EC) scale, which is consisted of 10 questions used in Johnston et al. (2001) [13]. These are parts of the consumers' ecological purchase behaviors scale developed by Roberts (1996), which is consisted of 30 items measuring socially responsible consumer behavior using two dimensions; societal and ecological concerns. The question is asking respondents to rate the veracity of various statements with respect to their purchase behavior and its connection to environmental product attributes. It is five-point Likert type scale which denotes 1 as "never agree" to 5 as "always agree."

\section{Model Structure}

The study is used a random parameter logit (RPL) model [14, 15] based on the random utility theory which is central to the concept of choice modeling. The basic assumption underlying the random utility approach to choice modeling is that decision makers are utility maximizers, which implies that given a set of alternatives, decision makers select the alternative that maximizes their utility. The utility of an alternative for an individual $(U)$ cannot be observed; however, it may be assumed to consist of a deterministic (observable) component $(V)$ and a random error (unobservable) component $(\varepsilon)$. Formally, an individual $q$ 's utility of alternative $i$ in each of $t$ choice set can be expressed as $U_{i q t}=V_{i q t}+\varepsilon_{i q t}=\beta^{\prime}{ }_{q} X_{i q t}+\varepsilon_{i q t}$. The density of $\beta^{\prime}{ }_{q}$ is denoted as $f(\beta \mid \theta)$, where $\theta$ is a vector of the true parameters of the taste distribution. $X_{i q t}$ denotes the explanatory variables of $V_{i q t}$ for alternative $i$, individual $q$ and choice set $t$. The random error component $\varepsilon_{i q t}$ is assumed to follow a type I extreme value (EV1) distribution and to be independently and identically distributed (IID). The conditional probability of alternative $i$ for individual $q$ in choice set $t$ is expressed as follows:

$$
P_{i q t}\left(\beta_{q}^{\prime}\right)=\frac{\exp \left({\beta^{\prime}}_{q{ }^{X} i q t}\right)}{\sum_{j=1}^{J} \exp \left({\beta^{\prime}}_{q^{X}}{ }_{j q t}\right)}
$$


The probability of the observed sequence of choices conditional on knowing $\beta^{\prime}{ }_{q}$ is expressed as follows:

$$
S_{q}\left(\beta_{q}^{\prime}\right)=\prod_{t=1}^{T} P_{q i(q, t) t}\left(\beta_{q}^{\prime}\right)
$$

where $i(q, t)$ represents the alternative selected by individual $q$ on choice set $t$. The unconditional probability of the observed sequence of choices for individual $q$ is the integral of the conditional probability over all possible variables of $\beta^{\prime \prime}$ and can be expressed as follows:

$$
P_{q}(\theta)=\int S_{q}(\beta) f(\beta \mid \theta) d \beta .
$$

In most applications, the density $f(\beta \mid \theta)$ is specified to be normal or lognormal: $\beta$ $\sim N(b, W)$ or $\ln \beta \sim N(b, W)$, where the mean, $b$, and covariance, $W$, are estimated. In this study, we use a normal density.

Based on the above discussion, the main effect in Model 1 and the main effect with interaction in Model 2 are estimated using RPL model with the inclusion of socioeconomic characteristics. Therefore, the two indirect utility functions are as follows:

Model 1: $V_{i q}=\beta_{1}$ Price $_{i}+\beta_{2} \mathrm{CO}_{i}$,

Model 2: $V_{i q}=\beta_{1}$ Price $_{i}+\beta_{2} \mathrm{CO}_{i}+\sum_{k=1}^{K} \delta_{k} \mathrm{CO}_{i} \times$ Socio $_{k q}$.

where Price $_{i}$ is the price of orange $i, \mathrm{CO}_{i}$ is the $\mathrm{CO}_{2}$ emission from orange $i$, and $\mathrm{CO}_{i} \times$ Socio $_{k q}$ is the interaction term of the $\mathrm{CO}_{2}$ emission from orange $i$ with a dummy variable indicating socioeconomic characteristics $k$ of individual $q$, including the EC scale. $\beta_{1}, \beta_{2}$, and $\delta_{k}$ are parameters that need to be estimated.

\section{$4 \quad$ Results}

The laboratory experiment was conducted at the Osaka University with 104 respondents (63 non-students and 41 students) during November at the beginning of the season of the orange. No one participated in more than one session. Each session lasted for approximately 60 minutes. The average earnings in experiment was 1,407 JPY.

Table 2 summarizes the result estimated from LIMDEP 9.0 and NLOGIT 4.0. In the RPL model, a simulated maximum likelihood estimator is used in order to estimate the models by employing Halton draws with 500 replications [16, 17].

First result is the main effect of Price and $\mathrm{CO}_{2}$. The variable Price is the fix parameter in the model because a price coefficient is known to be negative for every consumer. However, since the variable $\mathrm{CO}_{2}$ is not known, it is assumed as a random parameter and specified to be normally distributed $[14,16]$. The estimates of the two variables, Price and $\mathrm{CO}_{2}$, indicate significantly negative signs at $1 \%$ levels. These results imply that all the respondents prefer to purchase oranges whose price is cheaper and $\mathrm{CO}_{2}$ is lower. The marginal WTP for the reduction of $1 \mathrm{~g}$ of $\mathrm{CO}_{2}$ emission per an orange is 0.57 . 
Table 1. The random parameter logit regression results

\begin{tabular}{lcc}
\hline Variable & Main effect & $\begin{array}{c}\text { Main effect with } \\
\text { interactions }\end{array}$ \\
\hline Price & $-0.12 * * *(0.01)$ & $-0.12 * * *(0.01)$ \\
$\mathrm{CO}_{2}$ & $-0.07 * * *(0.01)$ & $-0.04 *(0.02)$ \\
$\mathrm{CO}_{2}$ : Standard deviation & $0.08 * * *(0.02)$ & $0.07 * * *(0.02)$ \\
$\mathrm{CO}_{2}$ : Marginal WTP (mean) & 0.57 & 0.33 \\
{$[95 \%$ confidential bounds] } & {$[0.55 ; 0.58]$} & {$[0.32 ; 0.34]$} \\
$\mathrm{CO}_{2} *$ High EC & & $-0.05 * * *(0.01)$ \\
$\mathrm{CO}_{2} *$ Female & & $-0.04 * *(0.02)$ \\
$\mathrm{CO}_{2} *$ Over 30 & & $0.02(0.02)$ \\
$\mathrm{CO}_{2} *$ High Income & & $-0.01(0.01)$ \\
$\mathrm{CO}_{2} *$ University & & $0.02(0.02)$ \\
$\mathrm{Log}_{\text {likelihood }}$ & -1107.62 & -1093.73 \\
$\mathrm{McFadden}$ ( $R^{2}$ & 0.19 & 0.20 \\
$\mathrm{Observations}$ & 1248 & 1248 \\
\hline
\end{tabular}

Notes: Standard errors are in parentheses. ${ }^{* * *}, * *$, and $*$ denote that the parameters are different from zero at the $1 \%, 5 \%, 10 \%$ significance levels, respectively.

Table 2. The dummy variables

\begin{tabular}{lll}
\hline Variables & Definition & Average \\
\hline High EC & 1: more than the median (30); 0: otherwise. & $0.49(0.50)$ \\
Female & 1: female; 0: male & $0.65(0.48)$ \\
Over 30 & 1: more than 30 years old; 0: otherwise. & $0.58(0.49)$ \\
High Income & 1: more than the median; 0: otherwise. & $0.49(0.50)$ \\
University & 1: graduation university; 0: otherwise & $0.86(0.35)$ \\
\hline
\end{tabular}

Notes: Standard errors are in parentheses. Median of high income is 5,500,000 JPY.

Next result is the main effect with the interactions of $\mathrm{CO}_{2}$. Here there is the main hypothesis such that consumers with higher EC scales exhibit higher WTP for reduction of $\mathrm{CO}_{2}$. The estimation model is added the five interaction variables to the two variables Price and $\mathrm{CO}_{2}$; High EC, Female, Over 30, High Income, and University. These variables are summarized in Table 2. Since spearman correlation rank-tests show significantly positive correlations at the $1 \%$ level in any combinations of EC, $\mathrm{EK}$, and EB, EC is used as a representative variable for the evaluation of consumers' environmental consciousness.

The results are as follows. Consumers have significantly negative coefficients for the increasing $\mathrm{CO}_{2}$. The consumers with higher environmental consciousness exhibit higher WTP for reduction of $\mathrm{CO}_{2}$ than those with lower environmental consciousness, which supports the main hypothesis. The result implies that the carbon footprint mitigate the emissions caused from the long distance transportation and enhance the local food production and service systems. 


\section{$5 \quad$ Conclusions and Discussions}

This study investigates the relationship between consumers' environmental consciousness and their valuations for the carbon footprint on daily food products by using the choice method in the real buying experiment. The results support the main hypothesis such that consumers with higher environmental consciousness have a higher WTP for the reduction of $\mathrm{CO}_{2}$ in the experiment.

The oranges used in this study have the almost same production procedures so that their $\mathrm{CO}_{2}$ emissions are not so far. The largest difference in the $\mathrm{CO}_{2}$ emissions caused from the transportation because of the difference from the transportation distances. Although this study does not inform the breakdown of $\mathrm{CO}_{2}$, the result implies that consumers prefer for foods produced in the near areas because of reducing emissions from the transportation.

In this study, the difference of the distance in the production area causes the difference in the carbon dioxide emissions. The result implies that the carbon footprint has a power to enhance the local food productions for the local consumptions and reduce the emissions caused from the long distance transportation.

Since this study investigates the value of reduction for the $\mathrm{CO}_{2}$ emissions on foods in the real buying experiment, a question is created as future works. That question is whether the value in the hypothetical condition is more than that in the experiment, which is a hypothetical bias. A choice experiment has a hypothetical bias risk. Harrison and Rutström (2008) surveyed 35 studies and found hypothetical bias in all but 3 cases, which implies that researchers rarely find a situation without hypothetical bias [18]. In the food market, Lusk and Schroeder (2004) found it for beef ribeye steak [19], and Chang et al. (2009), for ground beef and wheat flour [20]. Most recently, Aoki et al. (2010) found it in sodium nitrite information on hams. Hypothetical bias causes policy makers to suspect the credibility of policy evaluation data.

Acknowledgements. This study supported by Grant-in-Aid for JSPS Fellows and by the Japanese Ministry of Education, Culture, Sports, Science and Technology (the Global COE Program of Human Behavior and Socioeconomics Dynamics).

\section{References}

1. Onozaka, Y., Mcfadden, D.T.: Does Local Labeling Complement or Compete with Other Sustainable Labels? A Conjoint Analysis of Direct and Joint Values for Fresh Produce Claim. American Journal of Agricultural Economics 93(3), 693-706 (2011)

2. Roberts, J.A.: Green Consumers in the 1990s: Profile and Implications for Advertising. Journal of Business Research 36, 217-231 (1996)

3. Louviere, J.J., Hensher, D.A., Swait, J.D.: tated Choice Methods: Analysis and Application. Cambridge University Press, Cambridge (2000)

4. Cason, T., Gangadharan, L.: Environmental labeling and incomplete consumer information in laboratory markets. J. Environ. Econ. Manage. 43, 113-134 (2002)

5. Disdier, A.C., Marette, S.: How do consumers in developed countries value the environment and workers' social rights in developing countries? Food Policy 37, 1-11 (2012) 
6. Disdier, A.C., Marette, S.: Globalisation issues and consumers' purchase decisions for food products: evidence from a laboratory experiment. Eur. Rev. Agric. Econ. 40(1), 23-44 (2013)

7. Marette, S., Messean, A., Millet, G.: Consumers' willingness to pay for eco-friendly apples under different labels: Evidences from a lab experiment. Food Policy 37, 151-161 (2012)

8. Huffman, W.E., Shogren, J.F., Rousu, M., Tegene, A.: Consumer willingness to pay for genetically modified food labels in a market with diverse information: Evidence from experimental auctions. J. Agric. Res. Econ. 28, 481-502 (2003)

9. Lusk, J.L., House, L.O., Valli, C., Jaeger, S.R., Moore, M., Morrow, J.L., Traill, W.B.: Effect of information about benefits of biotechnology on consumer acceptance of genetically modified food: evidence from experimental auctions in the United States, England, and France. Eur. Rev. Agric. Econ. 31, 179-204 (2004)

10. Noussair, C., Robin, W., Ruffieux, B.: Do consumers really refuse to buy genetically modified food? Econ. J. 114, 102-120 (2004)

11. Rousu, M., Huffman, W.E., Shogren, J.F., Tegene, A.: Effects and value of verifiable information in a controversial market: Evidence from lab auctions of genetically modified food. Econ. Inquiry 45, 409-432 (2007)

12. Aoki, K., Shen, J., Saijo, T.: Consumer reaction to information on food additives: evidence from an eating experiment and a field survey. J. Econ. Behavior Organ. 73, 433-438 (2010)

13. Johnston, R.J., Wessells, C.R., Donath, H., Asche, F.: Measuring consumer preferences for ecolabeled seafood: an international comparison. J. Agric. Res. Econ. 26(1), 20-39 (2001)

14. Train, K.: Recreation demand models with taste differences over people. Land Economics 74(2), 230-239 (1998)

15. Train, K.: Discrete choice methods with simulation. Cambridge university press (2003)

16. Revelt, D., Train, K.: Mixed logit with repeated choices: households' choices of appliance efficiency level. Rev. Econ. Stat 80(4), 647-657 (1998)

17. Train, K.: Halton Sequences for Mixed Logit. Economics Working Papers E00-278. University of California at Berkeley (2000)

18. Harrison, G.W., Rutström, E.E.: Experimental Evidence on the Existence of Hypothetical Bias in Value Elicitation Methods. In: Plott, C.R., Smith, V.L. (eds.) Handbook of Experimental Economics Results, vol. 1, ch. 81, pp. 752-767. Elsevier (2008)

19. Lusk, J., Schroeder, T.: Are choice experiments incentive compatible? A test with quality differentiated beef steaks. American Journal of Agricultural Economics 86(2), 467-482 (2004)

20. Chang, J., Lusk, J., Norwood, F.: How Closely Do Hypothetical Surveys and Laboratory Experiments Predict Field Behavior? American Journal of Agricultural Economics 91(2), 518-534 (2009) 